\title{
Unusual Occurrence of Diacyl Glyceryl Ethers in Liver Lipids from Two Species of Gonatid Squids*1
}

\author{
Kenji HaYASHI ${ }^{* 2}$ and Ken-ichi KaWASAKI ${ }^{* 3}$ \\ (Accepted August 22, 1984)
}

\begin{abstract}
The lipid compositions of the livers of two species of gonatid squids, Berryteuthis magister and Gonatopsis makko, caught in the Japan Sea, were investigated.

The livers yielded $22.4 \%$ lipids for $B$. magister and $28.0 \%$ for G. makko, each of which contained an unusually high percentage of diacyl glyceryl ethers $(49.1 \%$ and $69.5 \%$, respectively) and small amounts of steryl esters $(24.0 \%$ and $16.0 \%$, triglycerides $(7.1 \%$ and $0.9 \%)$ and phospholipids $(8.6 \%$ and $3.5 \%)$.

In the two species, the component glyceryl ethers were reasonably similar in composition, consisting mainly of saturates (64.6-70.1\%) and monoenes $(27.7-33.0 \%$ of 14-22 carbon atoms for the alkyl moiety. The principal components were as follows: 16:0 (58.3-58.5\%), 18:1 (23.2$27.7 \%), 18: 0(4.0-7.6 \%)$, and $20: 1(3.4-4.1 \%)$. In both species, the fatty acid compositions of diacyl glyceryl ethers consisted predominantly of monoenes with $18: 1$ acid $(28.2-46.6 \%)$ as the main component.

For $B$. magister, few differences were found in the percentages of the component fatty acids among the lipid classes of diacyl glyceryl ethers, steryl esters, triglycerides and phospholipids; and for G. makko few differences ware found among diacyl glyceryl ethers, steryl esters and phospholipids.
\end{abstract}

Glyceryl ethers of marine origin have proven useful as natural surface-active or softening agents in cosmetics and ointments. Recently, what is more remarkable is that diacyl glyceryl ethers obtained from the ratfish liver lipids act as intermediates in the synthesis of biologically active alkylacetoylglycerophosphocholine (a platelet activating factor). ${ }^{\text {i) }}$

To develop new marine medicinal or cosmetic resources, the characteristics of diacyl glyceryl ethers abundant in the flesh lipids of teleost fish, ${ }^{2}$ ) Seriollela sp. and $S$. punctata, and in the liver lipids of ratfish, ${ }^{3,4)}$ Hydrolagus novaezealandiae, H. barbouri and Rhinochimaera pacifica, and sharks, ${ }^{3,8}$ Dalatias licha and Squalus acanthias, have been described previously. In the present study it was found that the liver lipids of squids belonging to the family Gonatidae, Berryteuthis magister and Gonatopsis makko, are also good source of diacyl glyceryl ethers.

The present investigation deals with the lipid compositions and the component glyceryl ethers of the livers of the above two species of gonatid squids. In connection with this, the component glyceryl ethers of diacyl glyceryl ethers present in small amounts in the liver lipids of common squid Todarodes pacificus are compared with those of the gonatid species. The component fatty acids of diacyl glyceryl ethers, steryl esters, triglycerides and phospholipids for B. magister, G. makko, and $T$. pacificus were also determined.

\section{Experimental}

\section{Materials}

Three species of squids, B. magister, G. makko and T. pacificus, which were $427 \mathrm{~g}, 105 \mathrm{~g}$ and $241 \mathrm{~g}$ in body weight, respectively, were caught in the Japan Sea and kept in a frozen state until analysis. The livers from these squids were used for the lipid extraction.

\section{Extraction and Fractionation of Lipids}

The total lipids were extracted from the squid livers, following the method of BLIGH and DYER. ${ }^{\text {") }}$ Neutral lipids were then separated from phospholipids by means of chromatography on a silicic acid-Celite $545(2: 1 \mathrm{w} / \mathrm{w})$ column. The

*1 This study was partly presented at the annual meeting of the Japanese Society of Scientific Fisheries, Kyoto, October, 1983.

*2 Faculty of Fisheries, Hokkaido University, Hakodate 041, Japan（林蜸治：北海道大学水産学部）.

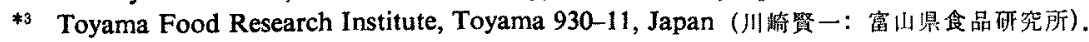


neutral lipids were eluted with chloroform and the phospholipids with methanol.

\section{Thin-Layer Chromatography (TLC)}

Qualitative and quantitative analyses of the neutral lipid constituents were carried out by TLC. Fractionation of steryl esters, diacyl glyceyl ethers and triglycerides of the neutral lipids was accomplished on prepared plates. Isopropylidene derivatives of glyceryl ethers were fractionated according to their degree of unsaturation on silicic acid plates impregnated with $15 \% \mathrm{AgNO}_{3}$. Thin layers of silicic acid $0.25 \mathrm{~mm}$ thick were used for analytical purposes; those with a thickness of $0.50 \mathrm{~mm}$ for preparative purposes. Mixtures of hexane, diethyl ether and acetic acid $(90: 10: 1$, $80: 20: 1, \mathrm{v} / \mathrm{v} / \mathrm{v}$ ) were used as developing solvents. After development, the plates were sprayed with $50 \%$ sulfuric acid or alcoholic dichlorofluorescein as visual reagents.

\section{Derivatization}

Fractionated diacyl glyceryl ethers were subjected to alkaline hydrolysis in $1 \mathrm{~N}$ ethanolic $\mathbf{K O H}$ by boiling under reflux for $1 \mathrm{~h}$. The unsaponifiables (glyceryl ethers) were extracted from the saponification mixture using diethyl ether. Isopropylidene derivatives of glyceryl ethers were prepared by acetonation at room temperature in the presence of $\mathrm{HClO}_{4}$ according to the method reported by MaLiNs et al. ${ }^{\text {s) }}$ Fatty acids of diacyl glyceryl ethers, steryl esters, triglycerides, and phospholipids, which were recovered after removal of the unsaponifiables by a routine method, were methylated with boron trifluoride-methanol. ${ }^{\text {) }}$ Prior to gas-liquid chromatography (GLC), further purification of these derivatives was carried out by TLC.

\section{Hydrogenation of Derivatives}

Samples were dissolved in hexane containing $5 \%$ palladium carbon catalyst and treated with hydrogen at atmospheric pressure and room temperature for $1 \mathrm{~h}$ to achieve complete hydrogenation.

\section{Gas-Liquid Chromatography}

Analyses by GLC were carried out using a Shimadzu model GC 6AM gas chromatograph, equipped with a dual hydrogen flame ionization detector. Isopropylidene derivatives of glyceryl ethers and fatty acid methyl esters were analysed on $1.5 \mathrm{~m} \times 3 \mathrm{~mm}$ i.d. glass columns packed with
$5 \%$ Silar 5CP on Gas Chrom Q (100/120 mesh) and with $10 \%$ DEGS on Chromosorb W AW (80/100 mesh), respectively. The operating conditions were as follows: Column temperatures were $230^{\circ} \mathrm{C}$ or $220-260^{\circ} \mathrm{C}$ (programmed rate, $2^{\circ} \mathrm{C} / \mathrm{min}$ ) for isopropylidene derivatives of glyceryl ethers, and $185^{\circ} \mathrm{C}$ for fatty acid methyl esters, respectively. Nitrogen was used as a carrier gas. The identification of the components of the aforementioned compound was accomplished by a comparison of their retention times with those of available standards, as well as by log-plots of retention times against the number of carbon atoms in the chain, before and after hydrogenation. Further identification of the main components of isopropylidene derivatives of glyceryl ethers was carried out by GLC-mass spectrometric analysis. Quantitative analysis was made on the basis of the percentage of the total area under each peak.

\section{Infrared Spectroscopy (IR)}

The IR spectra were determined using a Nippon Bunko model DS-301 spectrometer with $\mathrm{CCl}_{4}$ as a solvent.

\section{GLC-Mass Spectrometry (GLC-MS)}

The mass spectra were recorded using a Hitachi $60 \mathrm{M}$ instrument equipped with a glass column ( $2 \mathrm{~m} \times 3 \mathrm{~mm}$ i.d.) of $3 \%$ Silar $10 \mathrm{C}$ on Gas Chrom $\mathrm{Q}(100 / 120 \mathrm{mesh})$. The mass spectrometer was operated at $20 \mathrm{eV}$.

\section{Results and Discussion}

\section{Characteristics of Lipids}

The livers of the gonatid and common squids examined in this study yielded $22.4 \%$ lipids for B. magister, $28.0 \%$ for $G$. makko, and $37.8 \%$ for $T$. pacificus, respectively (Table 1 ). Of these, neutral lipids formed the predominant class, accounting for more than $91 \%$ of the total lipid contents; phospholipids accounted for less than $9 \%$.

The qualitative separation of the lipid constituents is illustrated in Fig. 1. The spot migrating slightly ahead of triglycerides on the silicic acid plates in Fig. 1-A and 1-B was seen as the major constituents of the liver lipids of the gonatid squids. $R f$ of this spot corresponded to that of diacyl glyceryl ethers. The liver lipids of the common squid (Fig. 1-C) contained major and minor constituents, corresponding to triglycerides 
Table 1. Lipid composition of the livers of gonatid and common squids

\begin{tabular}{lccc}
\hline & \multicolumn{2}{c}{ Gonatid squids } & \multicolumn{1}{c}{ Common squid } \\
\cline { 2 - 3 } & B. magister & G. makko & T. pacificus \\
\hline Liver lipids & $22.4 \%$ & $28.0 \%$ & $37.8 \%$ \\
\hline Steryl esters & $24.0 \%$ & $16.0 \%$ & $4.7 \%$ \\
Diacyl glyceryl ethers & 49.1 & 69.5 & 1.0 \\
Triglycerides & 7.1 & 0.9 & 77.7 \\
Fatty acids, Sterols and Partial glycerides & 11.2 & 10.1 & 9.2 \\
Phospholipids & 8.6 & 3.5 & 7.4 \\
\hline
\end{tabular}

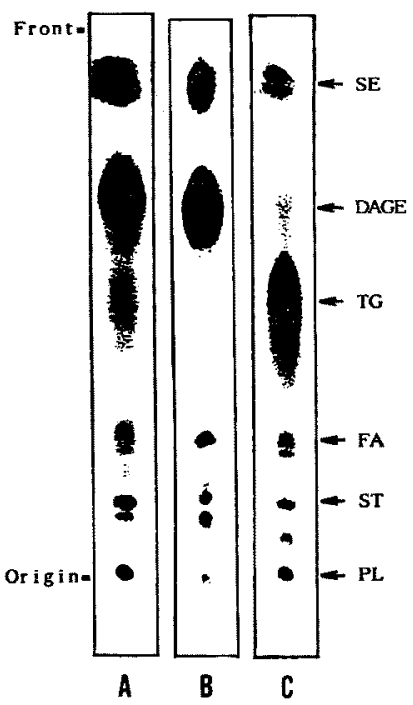

Fig. 1. Thin-layer chromatograms of the liver lipids of gonatid squids, B. magister (A) and G. makko (B), and of common squid $T$. pacificus (C). Adsorbent: silicic acid. Solvent: hexane, diethyl ether, acetic acid $(90: 10: 1, \mathrm{v} / \mathrm{v} / \mathrm{v})$. SE; steryl esters, DAGE; diacyl glyceryl ethers, TG: triglycerides, FA; fatty acids, ST; sterols, PL; phospholipids.

and diacyl glyceryl ethers, respectively.

The IR spectra of diacyl glyceryl ethers and glyceryl ethers obtained from the liver lipids gave the following characteristic absorptions: 1740 $\mathrm{cm}^{-1}(\mathrm{C}-\mathrm{O})$ and $1120 \mathrm{~cm}^{-1}$ (C-O-C) for the former compounds and $3440 \mathrm{~cm}^{-1}(-\mathrm{OH})$ and $1120 \mathrm{~cm}^{-1}(\mathrm{C}-\mathrm{O} \mathrm{C})$ for the latter ones. These absorptions were identical to those of the respective ether-linked compounds isolated from the flesh lipids of the deep-sea teleost fish, Seriollela sp., as previously reported by the authors. ${ }^{2}$

In GLC-MS analysis, the main components of isopropylidene derivatives of glyceryl ethers obtained from the liver lipids were found to give the
Table 2. Relative intensities ${ }^{* 1}$ of the principal peaks in mass spectra of the main components of isopropylidene derivatives of glyceryl ethers

\begin{tabular}{cccccc}
\hline \hline \multirow{2}{*}{$\begin{array}{c}\text { Glyceryl } \\
\text { ether*2 }\end{array}$} & \multicolumn{2}{c}{$\mathrm{M}^{+}$} & & \multicolumn{2}{c}{$\mathrm{M}^{+}-15$} \\
\cline { 2 - 3 } \cline { 5 - 6 } \cline { 5 - 6 } & $m / e$ & $\%$ & & $m / e$ & $\%$ \\
\hline $14: 0$ & 328 & 0.1 & & 313 & 33.7 \\
$16: 0$ & 356 & - & & 341 & 37.9 \\
$17: 0$ & 370 & - & & 355 & 32.8 \\
$18: 0$ & 384 & - & & 369 & 43.1 \\
$16: 1$ & 354 & 4.2 & & 339 & 29.5 \\
$18: 1$ & 382 & 4.3 & & 367 & 37.9 \\
$20: 1$ & 410 & 4.7 & & 430 & 32.1 \\
\hline *1 & Expressed as percent of base peak (m/e 101). \\
*2 Indicated by chain length and double bond of alkyl moiety. \\
M+: Molecular ion.
\end{tabular}

following characteristic peaks: molecular ion $\left(\mathrm{M}^{+}\right), \mathrm{M}^{+}-15\left(\mathrm{CH}_{3}\right)$ and $m / e 101$<smiles>CC1OC(C)(C)O1</smiles>

The lipid compositions of the livers of the two species of gonatid squids are given in Table 1. For comparison, data concerning the common squid are included in the same table. The liver lipids of the gonatid squids were characterized by high levels of diacyl glyceryl ethers (B. magister, $49.1 \%$; G. makko, $69.5 \%$ ) with only minute amounts of triglycerides $(7.1 \%$ and $0.9 \%$, respectively). Small amounts of steryl esters, fatty acids, sterols, and phospholipids were also detected in the liver lipids. On the contrary, the liver lipids of the common squid had large amounts of triglycerides $(77.7 \%)$ and minute amounts of diacyl glyceryl ethers $(1.0 \%)$, similar to various other marine organisms. No study has, hitherto, been reported on cephalopod species having an unusual abundance of diacyl glyceryl ethers in their livers. The diacyl glyceryl ether content $(49-70 \%)$ of the liver lipids of the gonatid squid examined was comparable to those of the ratfish liver lipids $(54-66 \%)^{3,4}$ ) and shark liver 
lipids $(28-45 \%),{ }^{3,8)}$ In addition, it is of interest to note that $B$. magister and $G$. makko belong to the same family, Gonatidae. Diacyl glyceryl ethers might, therefore, prove somewhat useful in regard to chemotaxonomic character.

\section{Glyceryl Ether Composition}

The main components of glyceryl ethers from diacyl glyceryl ethers of the liver lipids of the gonatid and common squids are given in Table 3. Glyceryl ethers of the gonatid species, $B$. magister and G. makko, were reasonably similar in composition. Even, as opposed to odd, numbers of carbon atoms, ranging from $\mathrm{C}_{14}$ to $\mathrm{C}_{22}$, prevailed for the alkyl moiety. The most predominant component for both gonatid squid species was 16: $0(58.3-58.5 \%)$ followed by $18: 1(23.2-27.7 \%)$ and 18: $0(4.0-7.6 \%)$, indicating a high content of saturates $(64.6-70.1 \%)$. The branched glyceryl ethers occurred only in small amounts (less than $2.2 \%$. As for the common squid T. pacificus, the component glyceryl ethers from diacyl glyceryl ethers of its liver lipids were similar in composition to those of the gonatid squids, except for the percentage of 14:0. Similar findings have been reported for the squid Loligo sp. in which phosphorylated glyceryl ethers $(7.9 \%$ of the phospholipid content) contained 16:0 component at high percentage $(59 \%) .{ }^{10)}$

It should be noted that the aforementioned
Table 3. Glyceryl ether composition of the liver lipids of gonatid and common squids

\begin{tabular}{|c|c|c|c|}
\hline \multirow{2}{*}{$\begin{array}{l}\text { Glyceryl } \\
\text { ether*1 }^{* 1}\end{array}$} & \multicolumn{2}{|c|}{ Gonatid squids } & \multirow{2}{*}{$\begin{array}{c}\begin{array}{c}\text { Common } \\
\text { squid }\end{array} \\
T . \text { pacificus }\end{array}$} \\
\hline & B. magister & G. makko & \\
\hline & & Peak area \% & \\
\hline $14: 0$ & 0.7 & 1.0 & 13.0 \\
\hline $15: 0$ & 0.3 & 0.5 & 2.4 \\
\hline $16: 0$ & 58.3 & 58.5 & 50.3 \\
\hline $17: 0$ & 1.9 & 0.6 & 1.4 \\
\hline $18: 0$ & 7.6 & 4.0 & 7.7 \\
\hline $19: 0$ & 1.1 & $\mathrm{tr}^{* 2}$ & tr \\
\hline 14: 1 & 0.1 & $\mathbf{t r}$ & 1.2 \\
\hline $16: 1$ & 0.5 & 0.5 & 2.2 \\
\hline $18: 1$ & 23.2 & 27.7 & 12.4 \\
\hline $20: 1$ & 3.4 & 4.1 & 2.8 \\
\hline 17: Obr*3 & - & 1.2 & - \\
\hline $18: 0 \mathrm{br}$ & 1.7 & 0.5 & 1.3 \\
\hline Saturates & 70.1 & 64.6 & 75.4 \\
\hline Monoenes & 27.7 & 33.0 & 20.9 \\
\hline Branched & 2.2 & 2.1 & 1.7 \\
\hline Unknown & - & 0.3 & 2.0 \\
\hline
\end{tabular}

diacyl glyceryl ethers of the liver lipids from the gonatid and common squids were extremely different in their component glyceryl ethers from those of the liver lipids of ratfish and sharks. That is, the component glyceryl ethers for ratfish

Table 4. Fatty acid composition of each lipid class of the liver lipids of gonatid and common squids

\begin{tabular}{|c|c|c|c|c|c|c|c|c|c|c|c|}
\hline \multirow{3}{*}{$\begin{array}{l}\text { Com- } \\
\text { ponent*1 }\end{array}$} & \multicolumn{7}{|c|}{ Gonatid squids } & \multirow{2}{*}{\multicolumn{4}{|c|}{$\frac{\text { Common squid }}{T \text {. pacificus }}$}} \\
\hline & \multicolumn{4}{|c|}{ B. magister } & \multicolumn{3}{|c|}{ G. makko } & & & & \\
\hline & DAGE & SE & TG & PL & DAGE & SE & PL & DAGE & SE & TG & PL \\
\hline & \multicolumn{11}{|c|}{ Peak area $\%$} \\
\hline $14: 0$ & 0.9 & 0.7 & 2.2 & 1.1 & 4.4 & 21.6 & 9.0 & 3.4 & 4.0 & 5.0 & 3.9 \\
\hline $16: 0$ & 4.9 & 2.9 & 12.8 & 18.2 & 5.4 & 8.3 & 15.8 & 9.0 & 8.3 & 20.6 & 43.8 \\
\hline $18: 0$ & 1.6 & 0.9 & 5.2 & 5.5 & 1.3 & 1.5 & 2.1 & 2.1 & 1.9 & 4.0 & 10.7 \\
\hline $16: 1$ & 1.9 & 3.4 & 3.1 & 2.1 & 4.9 & 7.6 & 3.3 & 5.2 & 8.0 & 4.9 & 3.6 \\
\hline $18: 1$ & 28.2 & 24.3 & 30.7 & 12.2 & 46.6 & 23.0 & 12.2 & 16.8 & 17.6 & 19.5 & 11.4 \\
\hline $20: 1$ & 12.5 & 9.2 & 13.1 & 9.6 & 13.8 & 7.9 & 9.0 & 7.9 & 5.8 & 6.5 & 8.4 \\
\hline $22: 1$ & 5.1 & 3.7 & 5.5 & 1.1 & 0.1 & 0.6 & 0.7 & 2.4 & 1.8 & 2.4 & 1.1 \\
\hline $20: 4$ & 3.4 & 6.2 & 3.6 & 9.4 & 10.0 & 9.9 & 5.1 & 2.8 & 2.2 & 1.9 & 1.4 \\
\hline $20: 5$ & 9.5 & 14.1 & 6.8 & 17.8 & $\operatorname{tr}^{* 2}$ & 1.9 & 17.2 & 9.5 & 14.1 & 8.2 & 4.5 \\
\hline $22: 6$ & 21.1 & 27.6 & 6.8 & 16.8 & 0.4 & 18.2 & $\operatorname{tr}$ & 32.8 & 27.4 & 18.5 & 4.4 \\
\hline Saturates & 9.2 & 6.1 & 22.3 & 27.2 & 17.0 & 36.6 & 27.7 & 16.5 & 16.6 & 31.4 & 61.7 \\
\hline Monoenes & 49.6 & 42.9 & 54.5 & 25.9 & 67.8 & 43.2 & 26.8 & 34.2 & 35.4 & 35.2 & 26.5 \\
\hline Polyenes & 41.2 & 51.0 & 23.2 & 46.9 & 14.9 & 19.8 & 45.1 & 49.3 & 48.0 & 33.4 & 11.8 \\
\hline
\end{tabular}


and sharks are rich in monoenes with $18: 1 \mathrm{com}$ ponent $(53.7-63.9 \%)^{3-6)}$

\section{Fatty Acid Composition}

Fatty acid compositions of diacyl glyceryl ethers of the gonatid and common squids are given in Table 4. For comparison, fatty acid compositions of steryl esters, triglycerides and phospholipids of the liver lipids for the three species of squids are included in the same table. For the gonatid squids, B. magister and G. makko, the fatty acid compositions of diacyl glyceryl ethers consisted predominantly of monoenes with $18: 1$ acid $(28.2-46.6 \%)$ as the main component. Also, these lipid classes were roughly similar in the fatty acid compositions. However, diacyl glyceryl ethers of G. makko were extremely different in the component fatty acid percentages from those of $B$. magister and $T$. pacificus. While G. makko showed 20:5 and 22: 6 acids at a level of $0.4 \%$, the other two species contained 30.6 $42.3 \%$ of these acids.

Few differences in the percentages of the component fatty acids were found among the lipid classes of diacyl glyceryl ethers, steryl esters, triglycerides and phospholipids for the squid species, B. magister, G. makko and $T$. pacificus.

In conclusion, the liver lipids of the gonatid squids, B. magister and G. makko, contain glyceryl ethers rich in the 16:0 component at an unusually high concentration. Taking into consideration at the potential resources of $\boldsymbol{B}$. magister ${ }^{11,12)}$ it is recommended that the liver lipids of this gonatid squid be made available for use as a new source for the isolation of glyceryl ethers.

\section{References}

1) T. Muramatsu, N. Totani, and H.K. Mangold: Chem. Phys. Lipids, 29, 121-127 (1981).

2) K. Hayashi and T. Takagi: Bull. Japan. Soc. Sci. Fish., 44, 917-923 (1978).

3) K. Hayashi and T. TAKagi: Bull. Japan. Soc. Sci. Fish., 46, 855-861 (1980).

4) K. Hayashi, T. Takagi, and M. Kitagawa: Bull. Japan. Soc. Sci. Fish., 49, 777-782 (1983).

5) K. Hayashi and T. Takagi: Bull. Japan. Soc. Sci. Fish., 47, 281-288 (1981).

6) K. Hayashr: Bull. Fac. Fish. Hokkaido Univ., 34, 250-259 (1983).

7) E. G. Bligh and W. J. Dyer: Can. J. Biochem. Physiol., 37, 911-917 (1959).

8) D. C. Malins, J. C. Wekell, and C. R. Houle: J. Lipid Res., 6, 100-105 (1965).

9) W. R. Morrison and L. M. SMith: J. Lipid Res., 3, 600-608 (1962).

10) R.W. Lewrs: Comp. Biochem. Physiol., 19, 363-377 (1966).

11) S. Kasahara, T. Nazumi, T. Shimizu, and $M$. Hamare: Bull. Jap. Sea Reg. Fish. Res. Lab., 29, 159-178 (1978).

12) T. OKutani: Aquabiology, 14, 217-221 (1981). 